\title{
Biofertilizer and biostimulant properties of the microalga Acutodesmus dimorphus
}

\author{
Jesus Garcia-Gonzalez ${ }^{1,2}$ - Milton Sommerfeld ${ }^{2,3}$
}

Received: 14 January 2015 / Revised and accepted: 18 May 2015 /Published online: 29 May 2015

(C) The Author(s) 2015. This article is published with open access at Springerlink.com

\begin{abstract}
Microalgae represent a potential sustainable alternative for the enhancement and protection of agricultural crops. Cellular extracts and dry biomass of the green alga Acutodesmus dimorphus were applied as a seed primer, foliar spray, and biofertilizer, to evaluate seed germination, plant growth, and fruit production in Roma tomato plants. A. dimorphus culture, culture growth medium, and different concentrations $(0,1,5,10,25,50,75$, and $100 \%)$ of aqueous cell extracts in distilled water were used as seed primers to determine effects on germination. Seeds treated with A. dimorphus culture and with extract concentrations higher than $50 \%\left(0.75 \mathrm{~g} \mathrm{~mL}^{-1}\right)$ triggered faster seed germination2 days earlier than the control group. The aqueous extracts were also applied as foliar fertilizers at various concentrations $(0,10,25,50,75$, and $100 \%)$ on tomato plants. Extract foliar application at $50 \%\left(3.75 \mathrm{~g} \mathrm{~mL}^{-1}\right)$ concentration resulted in increased plant height and greater numbers of flowers and branches per plant. Two dry biomass treatments (50 and $100 \mathrm{~g}$ ) were applied 22 days prior to seedling transplant and at the time of transplant to assess whether the timing of the
\end{abstract}

Milton Sommerfeld

Milton.Sommerfeld@asu.edu

Jesus Garcia-Gonzalez

jgarciag@asu.edu

1 Department of Applied Sciences and Mathematics, College of Letters and Sciences, Arizona State University, Mesa, AZ 85212, USA

2 Arizona Center for Algae Technology and Innovation, Arizona State University, 7418 East Innovation Way South, ISTB-3, Mesa, AZ 85212, USA

3 Environmental and Resource Management Program, Ira A. Fulton Schools of Engineering, Polytechnic School, Mesa, AZ 85212, USA biofertilizer application influenced the effectiveness of the biofertilizer. Biofertilizer treatments applied 22 days prior to seedling transplant enhanced plant growth, including greater numbers of branches and flowers, compared to the control group and the biofertilizer treatments applied at the time of transplant. The A. dimorphus culture, cellular extract, and dry biomass applied as a biostimulant, foliar spray, and biofertilizer, respectively, were able to trigger faster germination and enhance plant growth and floral production in Roma tomato plants.

Keywords Biostimulant · Biofertilizer · Foliar spray · Microalgae $\cdot$ Seed primer $\cdot$ Acutodesmus dimorphus

\section{Introduction}

In the coming decades, a crucial challenge will be meeting future food demands without causing further environmental degradation (Godfray, et al. 2010; Odegard and van der Voet 2014). The expanding global population, and their anticipated adoption of calorie-rich diets heavily comprised of dairy and meat products, represent added pressure to the Earth's resources. Society faces a challenge not only to increase agricultural production amidst global climate change, which threatens to diminish harvests in many areas of the world, but also to develop innovative technologies that increase agricultural yields, minimize inputs, and deter further environmental pollution (Tilman, et al. 2002; Foley, et al. 2011).

The overuse of synthetic agrochemicals has resulted in massive ecological degradation throughout the world, leading to ocean dead zones, eutrophication, soil infertility, and biodiversity loss (Köhler and Triebskorn 2013; Chagnon et al. 2014; Hallmann, et al. 2014; van der Sluijs et al. 2014). The 
use of microalgae as biofertilizers provides a possible solution. Biofertilizers are considered to be an environmentally friendly, cost-effective, sustainable alternative to synthetic fertilizers, for they not only enhance agricultural production but also diminish environmental pollution (Kawalekar 2013). Biofertilizers are products that contain living microorganisms or natural compounds derived from organisms such as bacteria, fungi, and algae that improve soil chemical and biological properties, stimulate plant growth, and restore soil fertility (Abdel-Raouf, et al. 2012).

Microalgae are multifunctional. They are capable of producing biomass that can be utilized for fuel, food, animal feed, and fertilizers (Metting 1990). Microalgae possess the potential to have a major influence on essential ecosystem services since they (i) can be cultivated in wastewater and agricultural runoff, recovering excess nutrients and reclaiming water for further use, and (ii) can sequester carbon dioxide and nitrous oxides from industrial sources, reducing greenhouse gas emissions (Brennan and Owende 2010). However, microalgae production must overcome several barriers in order for them to become economically viable, especially for production of biofuels (Brennan and Owende 2010; Mata, et al. 2010; Wijffels and Barbosa 2010; Borowitzka 2013; Pragya, et al. 2013).

One way to make microalgae biomass production more economically feasible, given current technologies, is to find potential applications for microalgae biomass or its byproducts that enable producers to offset production costs. Given that microalgae contain high levels of micronutrients and macronutrients essential for plant growth, they have potential application as biofertilizers. Several studies have established an association between greater nutrient uptake, higher biomass accumulation, and greater crop yields to the incorporation of microalgae biofertilizers (Shaaban 2001; Faheed and Abd-El Fattah 2008).

A study investigating the effects of algae extracts on seed germination has observed faster germination and greater growth of rice seeds (Shukla and Gupta 1967). Other more recent studies obtained similar results utilizing seaweed extracts on tomato and wheat seeds, although they have also observed growth inhibition with increasing extract concentrations (Kumar and Sahoo 2011; Kumari, et al. 2011; Hernández-Herrera, et al. 2013).

The cellular extracts and growth medium of several microalgae species have been shown to contain phytohormones (gibberellins, auxin, and cytokinin), which are known to play crucial roles in plant development (Tarakhovskaya, et al. 2007). Studies utilizing both the application of growth medium and cellular extracts from various algal species have shown a clear effect on plant development with the application of the algal extracts and the algal growth media (Burkiewicz 1987; Zhang, et al. 1989; Tarakhovskaya, et al. 2007; Stirk et al. 2013; Grzesik and Romanowska-duda 2014). Similar studies utilizing seaweed extracts as foliar applied sprays have observed an increase in plant biomass accumulation and greater crop yields (Kumari et al. 2011; Hernández-Herrera et al. 2013).

The USA is the second largest tomato producer in the world, producing over 13 million tonnes in 2012 (FAOSTAT 2014), and utilizes vast quantities of fertilizers to maintain annual production rates. The objectives of this study were to investigate the potential agricultural applications of the robust green microalga Acutodesmus dimorphus as a seed primer, a foliar fertilizer, and a soil amendment or biofertilizer and assess its effects on seed germination and plant growth of Roma tomatoes (Solanum lycopersicum var. Roma) under greenhouse conditions.

\section{Materials and methods}

Cultivation and harvesting The microalga Acutodesmus dimorphus (LARB-0414), isolated from the Phoenix, AZ, USA, metropolitan area, was cultivated outdoors in seven $1.22 \mathrm{~m} \times 14.63 \mathrm{~m}$ production row panel photobioreactors using standard BG-11 algae culture medium (Stanier, et al. 1971), bubbled with air mixed with $1 \%$ carbon dioxide, at the Arizona State University, Arizona Center for Algae Technology and Innovation (AzCATI). The biomass was harvested by centrifugation at day 14 of cultivation and was then frozen until used.

The frozen biomass was thawed in a cold room at $4{ }^{\circ} \mathrm{C}$ for $24 \mathrm{~h}$. Once thawed, the biomass was spread onto ten metal trays at a thickness of $1.5 \mathrm{~cm}$ and placed inside a freeze-dryer at $-40{ }^{\circ} \mathrm{C}$ to freeze-dry for approximately $48 \mathrm{~h}$. The dried biomass was then collected and stored in a cold room at $4{ }^{\circ} \mathrm{C}$.

Cell extracts One kilogram of the freeze-dried biomass was suspended in distilled (DI) water at a concentration of $150 \mathrm{~g} \mathrm{~L}^{-1}$. The suspension was stirred on a stirring plate for $10 \mathrm{~min}$ to allow the biomass to dissociate. The suspension was then processed through a Microfluidizer (M-110EH-30) - a mobile high-shear fluid processor at a flow rate of $450 \mathrm{~mL} \mathrm{~min}^{-1}$ at $172 \mathrm{mPa}$ to disrupt the cell wall and obtain the intracellular extracts. The resulting extract was then centrifuged at $8983 \times \mathrm{g}$ for $10 \mathrm{~min}$ at $22{ }^{\circ} \mathrm{C}$ to separate the cell extracts from the biomass residue. To minimize potential degradation, the resulting extract supernatant was collected in a flask covered with aluminum foil and stored in a cold room at $4{ }^{\circ} \mathrm{C}$. The biomass residue was also stored in the cold room for potential future use.

Seed primer experiment The cellular extracts, growth medium, and culture of $A$. dimorphus were screened to assess their ability to stimulate faster seed germination. The growth medium was obtained from a 14-day-old culture. A. dimorphus was 
cultivated indoors in a glass column photobioreactor $(250 \mathrm{~mL})$ using standard BG-11 algae culture medium (Stanier et al. 1971), bubbled with air mixed with $1 \%$ carbon dioxide. Two $50-\mathrm{mL}$ culture samples were obtained by collecting the supernatant after centrifugation at $3724 \times g$ for $10 \mathrm{~min}$.

Each treatment was replicated three times with ten seeds per replicate. The seeds were surface sterilized with $10 \mathrm{~mL}$ of $5 \%$ solution of sodium hypochlorite for $10 \mathrm{~min}$, rinsed twice with DI water, transferred to sterile Petri plates, and soaked in $10 \mathrm{~mL}$ of the respective treatment solutions for $24 \mathrm{~h}$. Following the 24-h priming (soaking) period, the seeds were placed between two 42.5-mm Whatman no. 1 filter papers and allowed to dry for $24 \mathrm{~h}$ at room temperature $\left(21{ }^{\circ} \mathrm{C}\right)$. Preceding the drying period, the seeds were transferred to a sterile $100-\mathrm{mm}$ Petri plate containing a moist $75-\mathrm{mm}$ Whatman no. 1 filter, which was soaked with $3 \mathrm{~mL}$ of DI water. The plates were incubated at room temperature at $21{ }^{\circ} \mathrm{C}$ under a 16 -h light/8-h dark cycle.

Seed germination was checked at 24-h intervals over a period of 10 days and counted as germinated if at least $2 \mathrm{~mm}$ of the radicle had emerged. The filter paper for all treatments was saturated as needed with $3 \mathrm{~mL}$ of DI water to maintain moisture. Using a caliper, root, shoot, and leaf lengths $(\mathrm{mm})$ were measured. Other measured variables included number of lateral roots, germination percentage (GP), and germination energy (GE). Germination percentage is an estimate of the viability of a population of seeds and was calculated as $\mathrm{GP}=$ (number of germinated seeds/total number of seeds) $\times 100$. Germination energy, a measure of the speed of germination and assumed to be a measure of the vigor of the seedling produced, was calculated according to HernándezHerrera et al. (2013), where $\mathrm{GE}=$ (number of germinating seeds/number of total seeds per treatment after germination for 3 days) $\times 100$.

Treatments were as follows:

1. Control, $0 \%$ extract ( $10 \mathrm{~mL}$ of DI water)

2. $\mathrm{S}_{1}, 1 \%$ concentration $(0.1 \mathrm{~mL}$ extract in $9.9 \mathrm{~mL}$ DI water)

3. $\mathrm{S}_{2}, 5 \%$ concentration $(0.5 \mathrm{~mL}$ extract in $9.5 \mathrm{~mL}$ DI water)

4. $\mathrm{S}_{3}, 10 \%$ concentration ( $1 \mathrm{~mL}$ extract in $9 \mathrm{~mL}$ DI water)

5. $\mathrm{S}_{4}, 25 \%$ concentration ( $2.5 \mathrm{~mL}$ extract in $7.5 \mathrm{~mL}$ DI water)

6. $\mathrm{S}_{5}, 50 \%$ concentration ( $5 \mathrm{~mL}$ extract in $5 \mathrm{~mL}$ DI water)

7. $\mathrm{S}_{6}, 75 \%$ concentration $(7.5 \mathrm{~mL}$ extract in $2.5 \mathrm{~mL}$ DI water)

8. $\mathrm{S}_{7}, 100 \%$ concentration $(10 \mathrm{~mL})$

9. $\mathrm{S}_{8}$, Acutodesmus growth medium $(10 \mathrm{~mL})$

10. $\mathrm{S}_{9}$, Acutodesmus culture $(10 \mathrm{~mL})$

Foliar spray experiment The experiment was performed under greenhouse conditions at approximately $28 \pm 2{ }^{\circ} \mathrm{C}$ and $85 \%$ relative humidity; treatments were arranged in a complete randomized block design. The experiment consisted of five treatments at various extract concentrations $(0,10,25,50$,
75 , and $100 \%$ ) diluted in distilled water (DI). Each treatment consisted of three replicates, one seedling per replicate. Each plant received two foliar applications; the first, at $50 \mathrm{~mL}$, was applied at the time of transplant and the second, at $100 \mathrm{~mL}$, 4 weeks later.

During foliar treatment applications, the soil surface was covered with aluminum foil to prevent spray runoff from coming in contact with the potting soil and being potentially available to be taken up by the roots. The sprays were conducted in the morning when the stomata were open due to water pressure, thus enabling greater foliar penetration. All plants were watered as needed throughout the experiment, except after foliar application when they were not watered for $24 \mathrm{~h}$.

Treatments were as follows:

*For 50-mL spray treatments, the concentrations below were reduced in half to total $50 \mathrm{~mL}$ volume

1. Control, $0 \%$ extract, $100 \mathrm{~mL}$ DI water

2. $\mathrm{T}_{1}, 10 \%(v / v) 10 \mathrm{~mL}$ extract in $90 \mathrm{~mL}$ DI water

3. $\mathrm{T}_{2}, 25 \%(v / v) 25 \mathrm{~mL}$ extract in $75 \mathrm{~mL}$ DI water

4. $\mathrm{T}_{3}, 50 \%(v / v) 50 \mathrm{~mL}$ extract in $50 \mathrm{~mL}$ DI water

5. $\mathrm{T}_{4}, 75 \%(v / v) 75 \mathrm{~mL}$ extract in $25 \mathrm{~mL}$ DI water

6. $\mathrm{T}_{5}, 100 \%(\mathrm{v} / \mathrm{v}) 100 \mathrm{~mL}$ extract

Biofertilizer experiment The biofertilizer experiment was conducted under greenhouse conditions at approximately 28 $\pm 2{ }^{\circ} \mathrm{C}$, in $85 \%$ relative humidity, from August through October 2014. Roma tomato (S. lycopersicum var. Roma) seeds were grown in sterilized potting soil, a mixture of vermiculite and peat moss. The seedlings were then transplanted after 22 days to $28-\mathrm{cm}$ pots (one seedling per pot). Two biofertilizer treatments of 50 and $100 \mathrm{~g}$ of dry algal biomass were applied 22 days prior to seedling transplant, into pots containing potting soil (peat moss:vermiculite:perlite), mixed thoroughly, and watered once a week for 3 weeks prior to seedling transplant. The other two 50- and 100-g biofertilizer treatments were applied at the time of seedling transplant. Each treatment had three replicates and was set up in a completely randomized block design. Plants were grown for a total of 8 weeks and were hand watered as needed. Plant height $(\mathrm{cm})$, number of flowers, number of branches, and early fruit development were recorded for all treatments. One sample per treatment was chosen at random to measure total fresh plant weight $(\mathrm{g})$.

Treatments were as follows:

1. Control (no biofertilizer)

2. $\mathrm{B}_{1}, 50 \mathrm{~g}$ of biofertilizer applied 22 days prior to transplant

3. $\mathrm{B}_{2}, 100 \mathrm{~g}$ of biofertilizer applied 22 days prior to transplant

4. $\mathrm{B}_{3}, 50 \mathrm{~g}$ of biofertilizer applied at the time of transplant

5. $\mathrm{B}_{4}, 100 \mathrm{~g}$ of biofertilizer applied at the time of transplant 
Statistical analysis Statistical analyses were conducted using StatPlus:mac LE programming (AnalystSoft Inc. 2009). All experiments were analyzed using a one-way analysis of variance (ANOVA), to test difference among the means. Post hoc $t$ test was used for analysis of significant difference between treatments: the level of significance was set at $P<0.05$.

\section{Results}

\section{Biostimulant}

The live $A$. dimorphus culture $\left(\mathrm{S}_{9}\right)$, the filtered growth medium $\left(\mathrm{S}_{8}\right)$, and $50 \%\left(\mathrm{~S}_{5}\right)$ and $100 \%\left(\mathrm{~S}_{7}\right)$ extract concentration treatments triggered faster seed germination-2 days earlier than the control group. The $A$. dimorphus culture treatment $\left(\mathrm{S}_{9}\right)$ was the only treatment to have at least half of the seeds germinate by the third day. On the fifth day, most treatments had reached full germination percentage (Fig. 1). Almost all treatments, with the exception of the growth medium $\left(\mathrm{S}_{8}\right)$ and the $25 \%\left(0.375 \mathrm{~g} \mathrm{~mL}^{-1}\right)$ extract concentration $\left(\mathrm{S}_{4}\right)$, had seeds that did not germinate. Because the majority of the seeds within these treatments did germinate, it was concluded that some of the seeds were not viable.

Germination energy calculations demonstrated a positive relationship between increasing extract concentrations and increasing speed of germination (germination energy). The greatest seed germination speed obtained with an extract treatment was with the $100 \%\left(1.5 \mathrm{~g} \mathrm{~mL}^{-1}\right)$ concentration $\left(\mathrm{S}_{7}\right)$ at $40 \%$, slightly surpassed by the growth medium $\left(\mathrm{S}_{8}\right)$ with $47 \%$ germination energy. However, the fastest germination speed at $63 \%$ was observed on seeds that were treated with A. dimorphus living culture $\left(\mathrm{S}_{9}\right)$ (Fig. 2).
The tomato seeds inoculated with $A$. dimorphus culture had greater lateral root development (Fig. 3) outperforming all other treatments. The number of lateral roots was somewhat variable across the extract concentration range. However, there was a general trend of more lateral roots with increasing extract concentration. The higher the number of lateral roots, the greater the plants' ability to acquire water and nutrients: hence, seeds inoculated with Acutodesmus culture would potentially accumulate greater plant biomass and result in greater crop yields.

\section{Foliar spray}

All foliar treatments resulted in greater plant growth compared to the control group. The $50 \%$ or $3.75 \mathrm{~g} \mathrm{~mL}^{-1}$ extract concentration $\left(\mathrm{T}_{3}\right)$ foliar spray $\left(7.5 \mathrm{~g} \mathrm{~mL}^{-1}\right.$ for $100 \mathrm{~mL}$ second application) led to greater flower development (Fig. 4a), a higher number of branches (Fig. 4b), and the greatest plant height (Fig. 4c). Foliar sprays of higher concentrations $\left(75 \%\left(\mathrm{~T}_{4}\right)\right.$ and $\left.100 \%\left(\mathrm{~T}_{5}\right)\right)$ resulted in less flower development, a lower number of branches, and a slight decrease in plant height compared to the $50 \%$ extract concentration foliar treatment (Table 1).

One plant sample per foliar treatment was chosen at random in order to measure the impact of foliar spray on total fresh plant weight $(\mathrm{g})$. The $50 \%$ or $3.75 \mathrm{~g} \mathrm{~mL}^{-1}$ treatment $\left(\mathrm{T}_{3}\right), 75 \%$ or $5.625 \mathrm{~g} \mathrm{~mL}^{-1}$ treatment $\left(\mathrm{T}_{4}\right)$, and $100 \%$ or $7.5 \mathrm{~g} \mathrm{~mL}^{-1}$ treatment $\left(\mathrm{T}_{5}\right)$ extract concentrations led to ca. five times greater total plant fresh weight (Fig. 5). However, additional spray concentrations beyond the $50 \%$ (3.75 $\left.\mathrm{g} \mathrm{mL}^{-1}\right)$ did not show much additional increase in plant weight.
Fig. 1 Seed germination percentage: seeds treated with Acutodesmus culture (S9), growth medium (S8), and cell extracts: $S 1$ $1 \%$ extract concentration, $S 25 \%$ extract concentration, S3 $10 \%$ extract concentration, $S 425 \%$ extract concentration, $S 550 \%$ extract concentration, $S 675 \%$ extract concentration, and $\mathrm{S} 7$ $100 \%$ extract concentration. All extract dilutions were with DI water

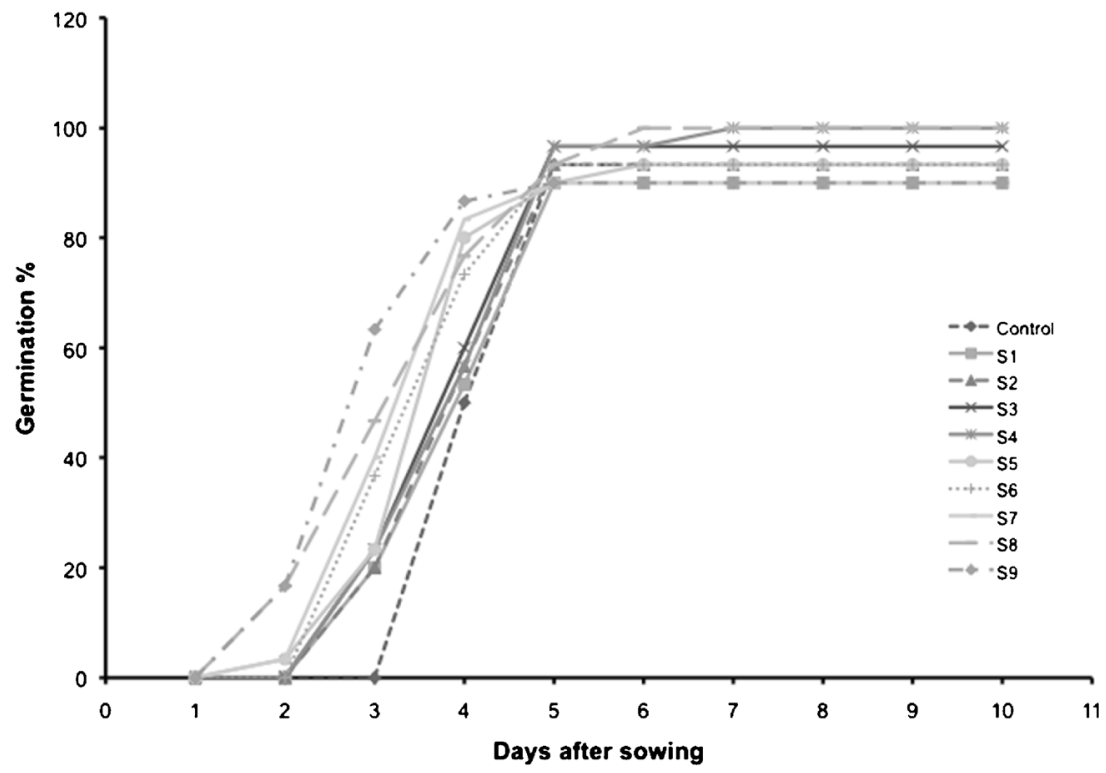


Fig. 2 Germination energy of seeds treated with Acutodesmus culture (S9), growth medium (S8), and cell extracts: S1 $1 \%$ extract concentration, $S 25 \%$ extract concentration, $S 310 \%$ extract concentration, $S 425 \%$ extract concentration, $S 550 \%$ extract concentration, $S 675 \%$ extract concentration, and $S 7$ $100 \%$ extract concentration. All extract dilutions were with DI water

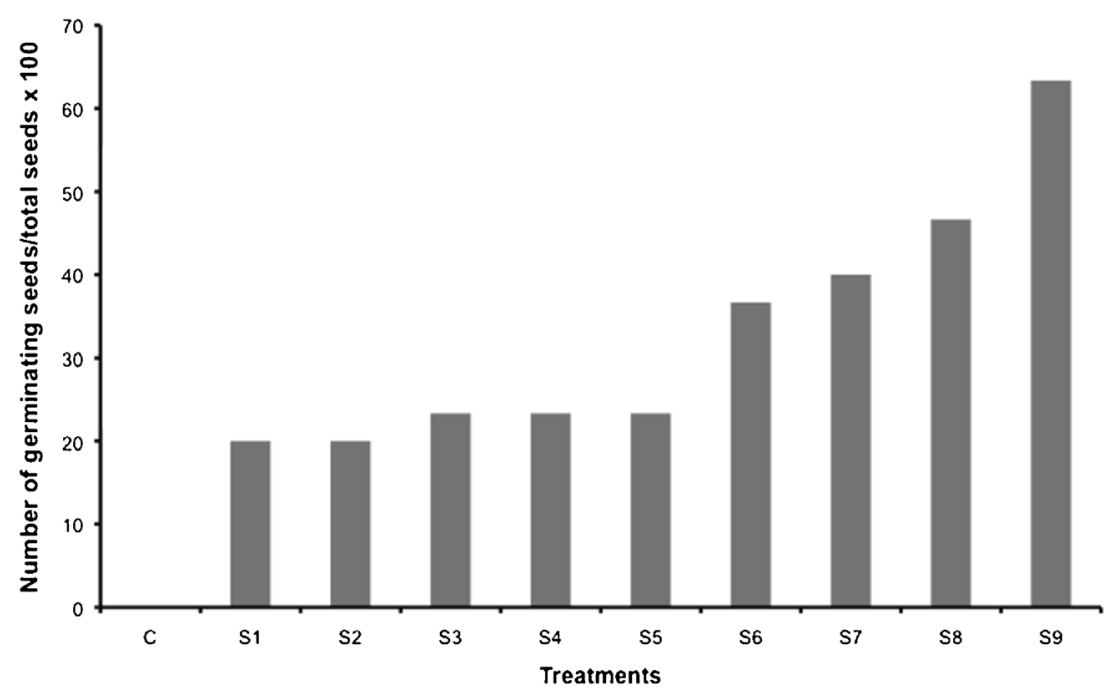

\section{Biofertilizer}

The results showed a significant difference between the biofertilizer treatments that were applied 22 days prior to seedling transplant $\left(\mathrm{B}_{1}, \mathrm{~B}_{2}\right)$ compared to those applied at the time of transplant $\left(B_{3}, B_{4}\right)$. Differences in several important growth parameters, such as the number of branches (Fig. 6a), number of flowers (Fig. 6b), and early fruit development (Fig. 6c), were observed. There were significant differences when the biofertilizer treatments were applied 22 days prior to transplant as compared to the control group and the biofertilizer treatments applied at the time of transplant.

Focusing only on the biofertilizer treatments applied 22 days prior to transplant, it was apparent that the 50- and 100 -g treatments or amendments $\left(B_{1}, B_{2}\right)$ yielded a greater average number of branches and flowers than the control group. However, the lower amendment concentration gave greater numbers of fruit set. The opposite was observed when the biofertilizer treatments were applied during seedling transplant, with the 100 -g biofertilizer treatment $\left(\mathrm{B}_{4}\right)$ generating plants with a slightly greater number of branches and flowers than the 50-g treatment $\left(B_{3}\right)$ (Fig. 6a, b).

When comparing the biofertilizer treatments applied during seedling transplant $\left(\mathrm{B}_{3}, \mathrm{~B}_{4}\right)$ with the control group, we observed that for branch development (Fig. 6a) and flower development (Fig. 6b), the 100-g treatment exceeded the control group, but did not reach the levels observed with the biofertilizer treatments applied 22 days in advance. With flower development (Fig. 6b), the biofertilizer treatments gave results similar to those of the control group. The results on early fruit setting indicated that application of the biofertilizer 22 days in advance increased early fruit set with both 50- and 100 -g treatments, and with the 100 -g treatment showing the greater early fruit set. A very low fruit set (less than that of the
Fig. 3 Effects of Acutodesmus culture (S9), growth medium (S8), and extract concentrations $(S 1-S 7)$ on lateral root development of tomato seedlings. $S 11 \%$ extract concentration, $S 2$ $5 \%$ extract concentration, $S 3$ $10 \%$ extract concentration, $S 4$ $25 \%$ extract concentration, $S 5$ $50 \%$ extract concentration, $S 6$ $75 \%$ extract concentration, and S7 $100 \%$ extract concentration. All extract dilutions were with DI water. Columns denoted by a different letter are significantly different at $P<0.05$. Values represent average $(n=10)$; bars represent standard error

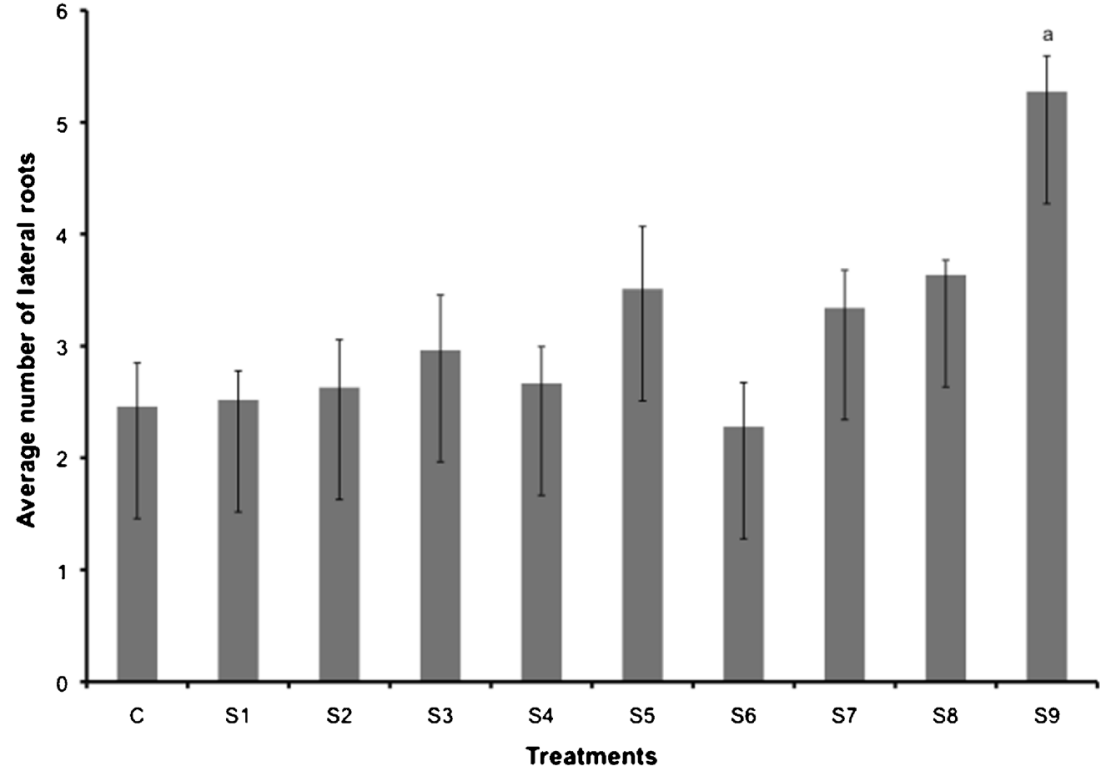


Fig. 4 a Effects of cell extracts as foliar treatments on flower development, $\mathbf{b}$ effects of foliar treatments on average number of branches, $\mathbf{c}$ effects of foliar sprays on average shoot length per treatment on tomato plants: $T 1$ $10 \%$ extract concentration, $T 2$ $25 \%$ extract concentration, $T 3$ $50 \%$ concentration, $T 475 \%$ concentration, and T5 $100 \%$ extract concentration. All extract dilutions were with DI water. Columns denoted by a different letter are significantly different at $P<0.05$. Values represent average $(n=3)$; bars represent standard error
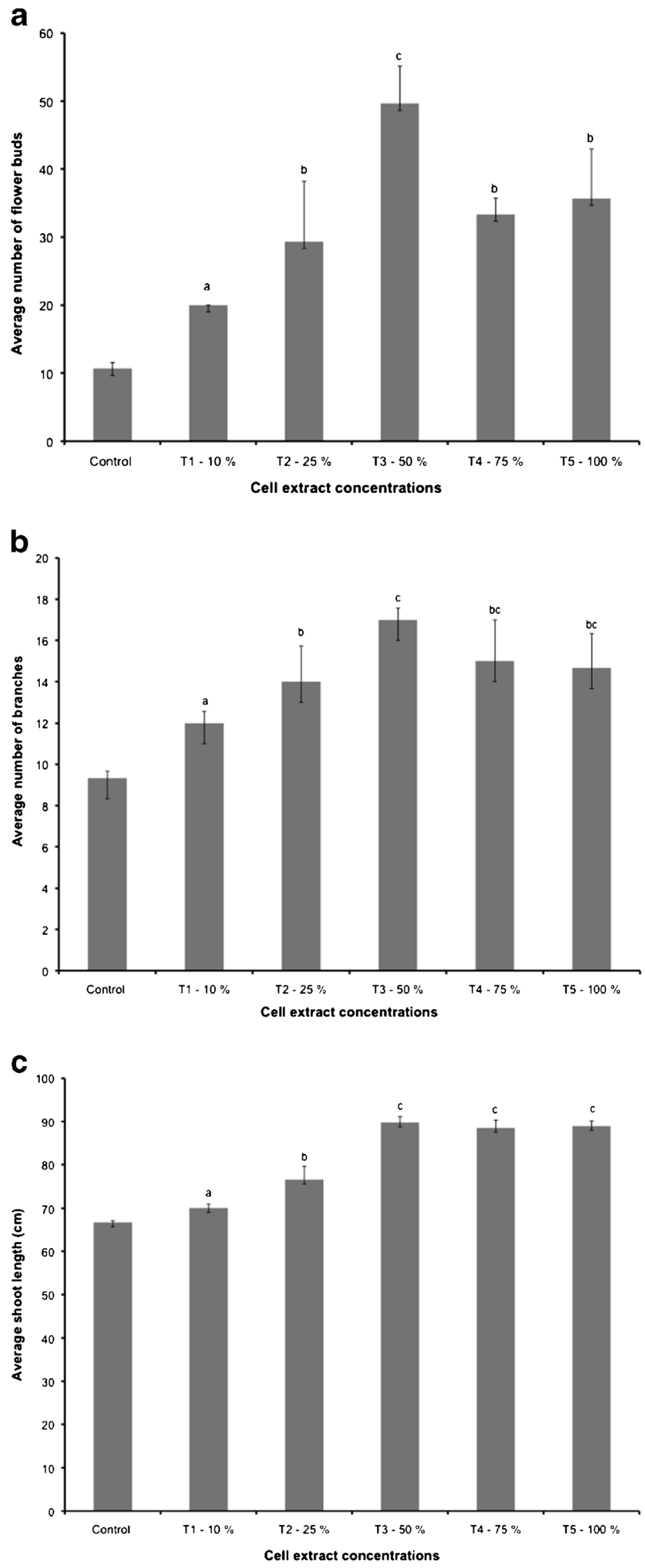
Table 1 Effects of extract foliar sprays on growth parameters of tomato plants

\begin{tabular}{lllcc}
\hline \multirow{2}{*}{ Treatments } & \multirow{2}{*}{$\begin{array}{l}\text { Concentrations (in DI water) } \\
\left(\mathrm{g} \mathrm{mL}^{-1}\right)\end{array}$} & \multicolumn{2}{l}{ Growth parameters } & \\
\cline { 3 - 5 } \cline { 3 - 4 } & & Number of flowers & Number of branches & Plant height (cm) \\
\hline Control & 0 & $10.67 \pm 0.882$ & $9.33 \pm 0.333$ & $66.68 \pm 0.367$ \\
$\mathrm{~T}_{1}-10 \%$ & 0.75 & $20.00 \pm 0.000$ & $12 \pm 0.577$ & $70.06 \pm 0.923$ \\
$\mathrm{~T}_{2}-25 \%$ & 1.875 & $29.33 \pm 8.838$ & $14 \pm 1.732$ & $76.62 \pm 2.986$ \\
$\mathrm{~T}_{3}-50 \%$ & 3.75 & $49.67 \pm 5.457$ & $17 \pm 0.577$ & $89.75 \pm 1.388$ \\
$\mathrm{~T}_{4}-75 \%$ & 5.625 & $33.33 \pm 2.404$ & $15 \pm 2.000$ & $88.48 \pm 1.845$ \\
$\mathrm{~T}_{5}-100 \%$ & 7.5 & $35.67 \pm 7.311$ & $14.67 \pm 1.667$ & $88.90 \pm 1.270$ \\
\hline
\end{tabular}

Values are average \pm standard error $(n=3)$ control) occurred with the biofertilizer application $\left(\mathrm{B}_{3}, \mathrm{~B}_{4}\right)$ at the time of seedling transplant (Fig. 6c). This could possibly be due to nutrient imbalance, caused by microbial nutrient immobilization. It is also important to note that due to the early termination of the experiment, total fruit yields were not obtained. Nevertheless, given the early fruit setting data, we can presume that both biofertilizer treatments applied 22 days prior to seedling transplant would have yielded greater fruit numbers, with the 100 -g biofertilizer treatment likely resulting in the highest yields.

General observations of the growing plants indicated differences in plant mass with the biofertilizer treatments. The results indicated that the biofertilizer treatments applied 22 days prior to seedling transplant $\left(\mathrm{B}_{1}, \mathrm{~B}_{2}\right)$ yielded significantly more biomass, having greater shoot and root fresh weights (Fig. 7). All biofertilized treatments led to higher total fresh weight compared to the control group. The two biofertilizer treatments applied 22 days prior to seedling transplant greatly exceeded the control group in biomass $(400+\mathrm{g}$ difference) and weighed approximately $350 \mathrm{~g}$ more than the biofertilizer treatments applied at the time of seedling transplant. There was little difference in biomass between the two biofertilizer treatments applied 22 days prior to transplant, with the 100 -g treatment $\left(B_{2}\right)$ showing a slightly greater total fresh plant weight than the 50 -g treatment $\left(B_{1}\right)$, a difference of approximately $15 \mathrm{~g}$.

\section{Discussion}

The vast majority of research on the agricultural applications of algae has focused on the use of cyanobacteria (blue-green algae) on rice fields for various reasons, the most important being their ability to fix atmospheric nitrogen to plantavailable forms (Irisarri, et al. 2001; Jha and Prasad 2006; Pereira et al. 2008; Sharma, et al. 2010), or on macroalgae (seaweeds), since they can be harvested from coastal areas and
Fig. 5 Effects of Acutodesmus dimorphus extracts as foliar sprays on total fresh plant weight (one sample per treatment chosen at random)

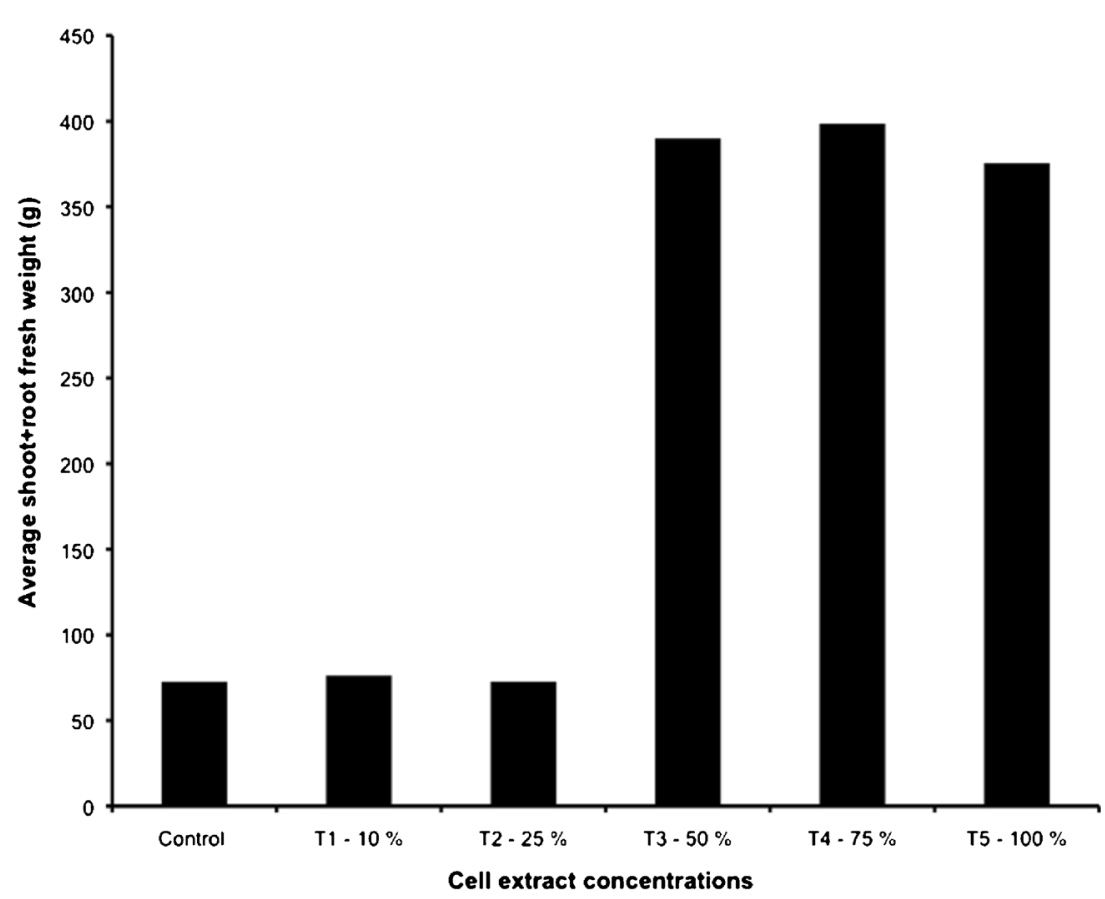


Fig. 6 a Effects of biofertilizer on branch development - number of branches per plant $(P=0.0002)$, b effects on number of flowers $(P=0.0001)$, and $\mathbf{c}$ effects on early fruit setting - number of fruits $(P=0.0129): B 150 \mathrm{~g} 22$ days prior to transplant, $B 2100 \mathrm{~g}$ 22 days prior to transplant, $B 3$ $50 \mathrm{~g}$ at the time of transplant, and B4 $100 \mathrm{~g}$ at the time of transplant. Columns denoted by a different letter are significantly different at $P<0.05$. Values represent average $(n=3)$; bars represent standard error a

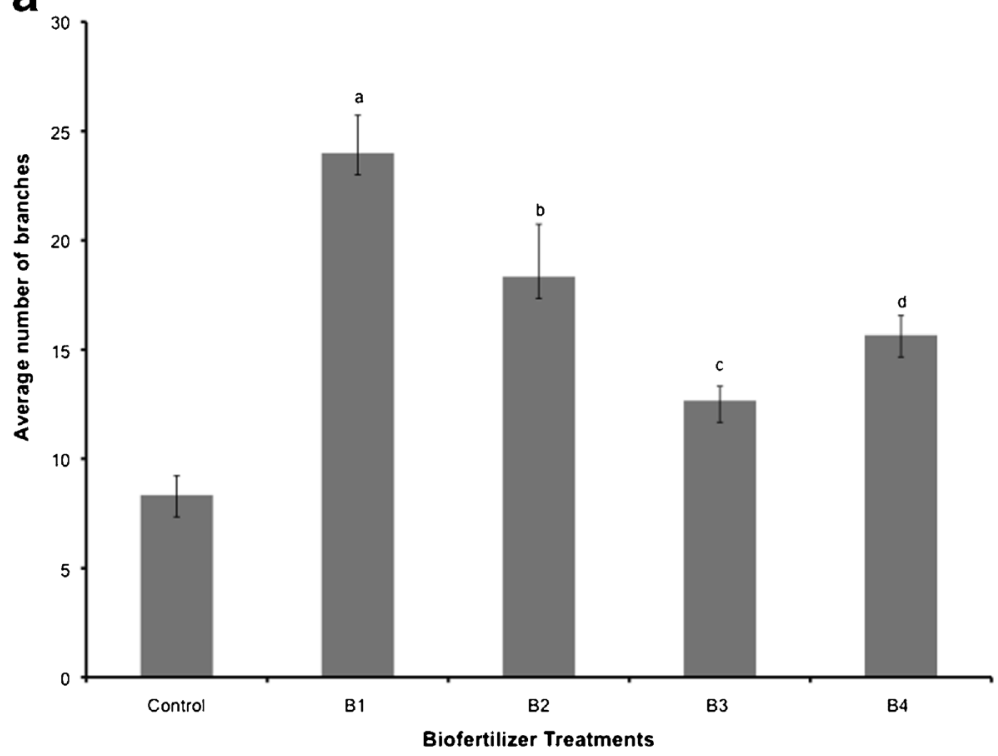

b
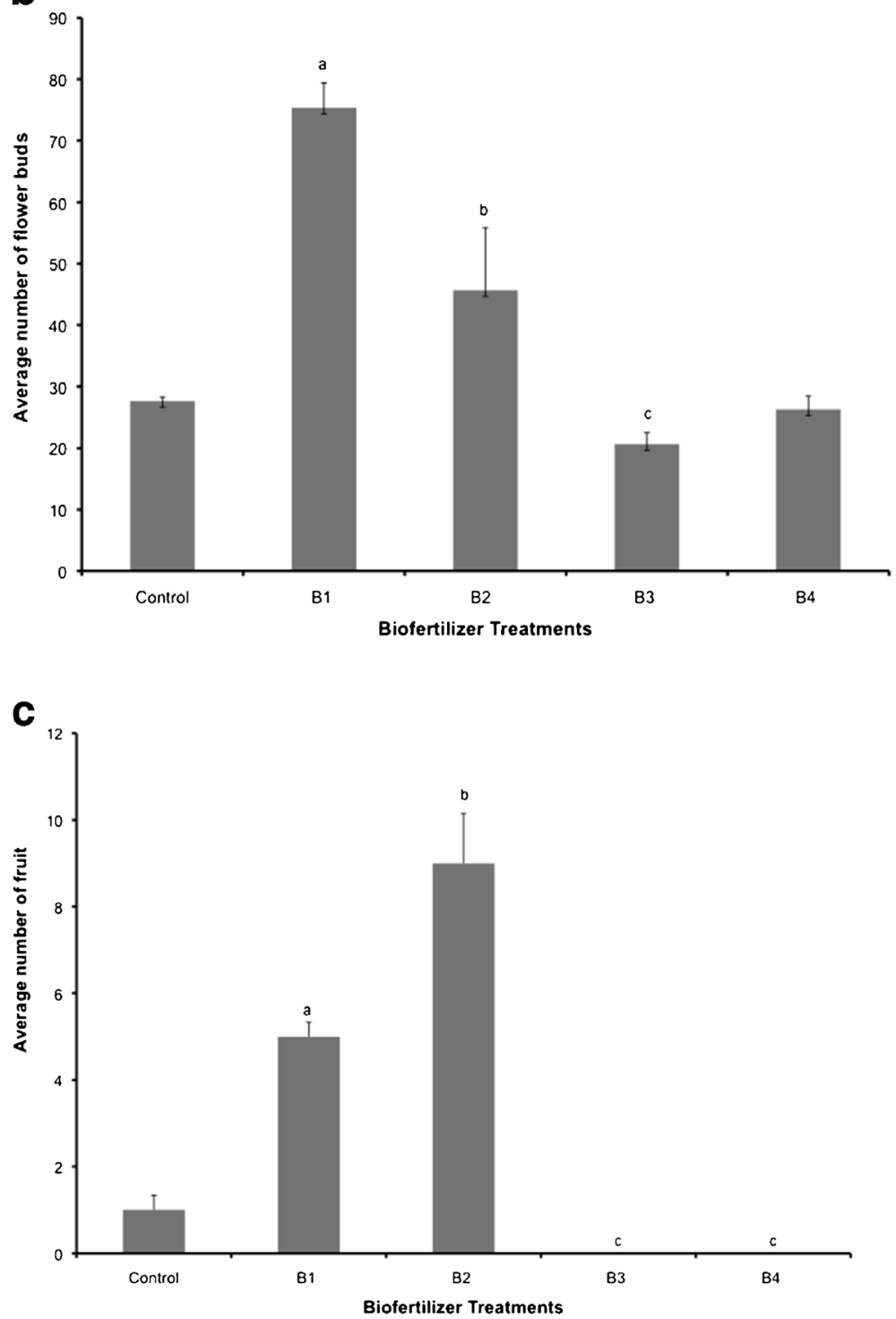
Fig. 7 Total fresh plant (shoot+ root) weight of samples selected at random from treatments: $B 1$ $50 \mathrm{~g} 22$ days prior to transplant, $B 2100 \mathrm{~g} 22$ days prior to transplant, $B 350 \mathrm{~g}$ at the time of transplant, and $B 4100 \mathrm{~g}$ at the time of transplant

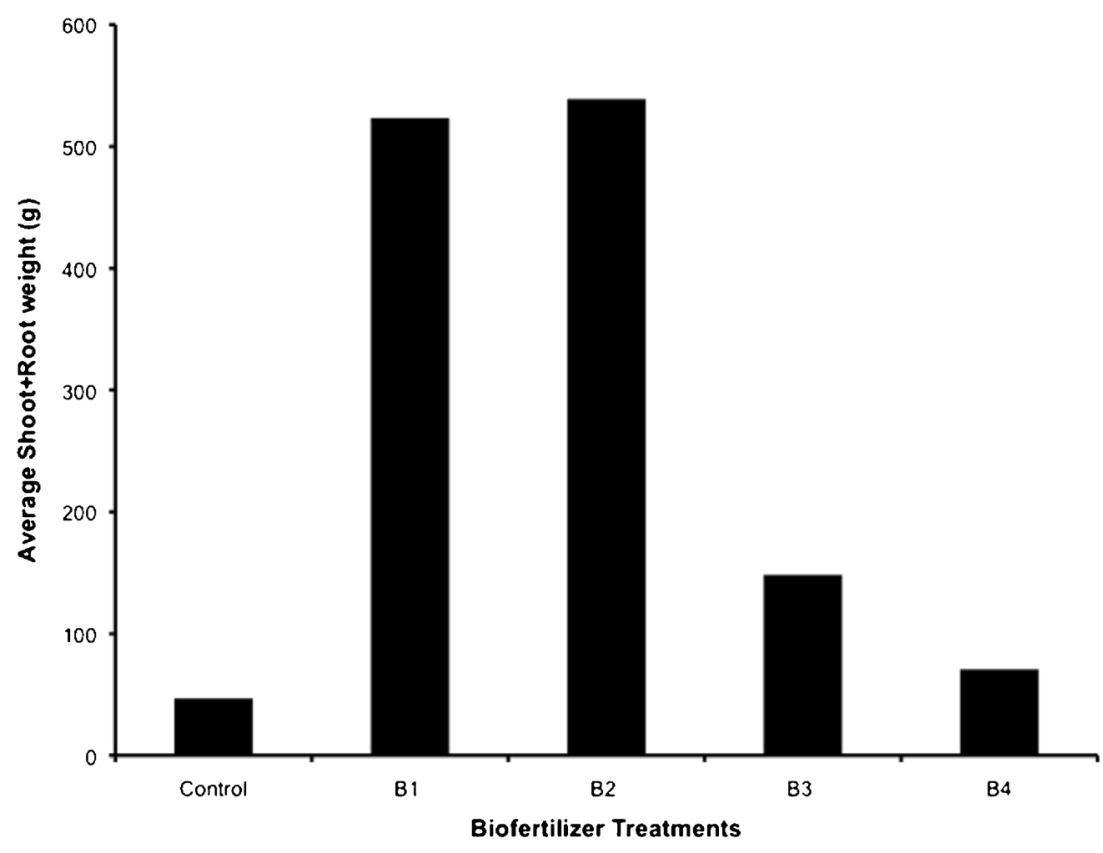

are easier to process compared to microalgae (Verkleij 1992; Zodape 2001).

The renewed interest in developing biofuels from microalgae has led to an increase in research for potential product and/or by-product applications that can make cultivation and production more economically feasible at mass scales. Most of the research on the potential by-product applications of microalgae has concentrated on bioactive compounds (nutraceuticals, antioxidants, and food active ingredients) due to their high retail values (Herrero, et al. 2006; Mendiola et al. 2007; Plaza et al. 2010; Rodríguez-Meizoso et al. 2010). We believe that there is a larger untapped market for the application of microalgae biomass or by-products as agrochemicals.

There is limited evidence on the application of live microalgae culture, cell extracts, and dry biomass as potential agrochemicals. To increase our knowledge about the agricultural applications of microalgae, the goal of this study was to evaluate whether the microalga $A$. dimorphus living culture, cell extracts, and dry biomass could be applied to tomato plants as a biostimulant, foliar spray, and biofertilizer.

Previous studies have shown that certain microalgal extracts enhance the growth of agricultural crops, which has been attributed to plant growth regulators (auxins, gibberellins, and cytokinins) and to high levels of macro- and micronutrients (Tarakhovskaya, et al. 2007). This study demonstrated that the application of $A$. dimorphus aqueous extracts, live culture, and dry biomass enhanced the germination, growth, and potential yield of tomato plants. Our study showed that the application of live $A$. dimorphus culture and aqueous cell extracts increased seed germination percentage in all treatments compared to the control group. The seeds treated with live $A$. dimorphus culture germinated faster, meaning the seedlings had the greatest vigor. Studies conducted on tomato seeds utilizing seaweed extracts at varying concentrations gave similar results. Hernández-Herrera et al. (2013) noticed that an extract concentration of $0.009 \mathrm{~g} \mathrm{~mL}^{-1}$ resulted in the highest germination percentage and the greatest plant growth, and that higher extract concentrations exhibited a negative effect on seed germination. Similarly, Kumar and Sahoo (2011) observed that seaweed extract concentrations greater than $20 \%$ resulted in smaller root lengths, a lower number of lateral roots, and shorter shoot length.

Foliar application of the aqueous cell extracts of $A$. dimorphus increased plant growth compared to the control group, with the $50 \%\left(3.75 \mathrm{~g} \mathrm{~mL}^{-1}\right)$ extract concentration yielding the highest results. Foliar sprays of greater extract concentrations 75 and $100 \%$ led to a decrease in growth compared to the $50 \%$ spray. Our results are comparable to those obtained by Hernández-Herrera et al. (2013), who observed smaller shoot lengths on foliar sprays of seaweed extracts at concentrations greater than $0.18 \mathrm{~g} \mathrm{~mL}^{-1}(0.4 \%)$, while Kumari et al. (2011) observed the opposite with greater plant growth with increasing seaweed extract concentrations.

Foliar sprays provide a more rapid nutrient utilization and enable faster correction of nutrient deficiencies compared to soil fertilizer applications. The greatest difficulty in supplying nutrients via foliar fertilization is in adequately applying the right quantity without damaging the leaves. Generally, the results have indicated a positive correlation between foliar extract applications and greater plant growth. Nevertheless, for foliar sprays to gain a greater acceptance for application in crop production, further studies need to be conducted since there are a plethora of factors (temperature, humidity, light 
intensity, nutrient concentration, surfactants, application rate, etc.) that may play a role in the efficiency of foliar applications (Haynes and Goh 1977; Kannan and Charnel 1986; Fernández and Eichert 2009).

In this study, tomato seedlings treated with dry A. dimorphus biomass (biofertilizer) clearly led to higher number of flowers and branches and early fruit development. There was a significant difference when the biomass was applied weeks prior to transplant, meaning that the biomass needs to be broken down in order to be readily available for plant uptake. Seedlings that received biofertilizer applications 22 days prior to transplant resulted in the greatest plant growth, the highest number of floral development, and early fruit setting, which could theoretically mean a greater crop yield. However, due to the early termination of our experiment, total crop yield data was not collected. Further studies should be conducted on utilizing whole and residual biomass (after oil extraction) to study whether it has the same stimulating growth effects, regardless of whether it is applied at the time of transplant or whether it needs to be applied earlier as seen with dry unprocessed (no oil extraction) biomass.

The application of live microalgae culture, aqueous cellular extracts, and dry biomass may not only increase plant growth but also make algae production systems more economically feasible. With increasing climate change, new innovations will be needed in order to enhance and protect agricultural crops throughout the world. The challenge to produce more food with limited resources makes microalgae a suitable alternative for enhancing and protecting agricultural production and delivering economic and environmental benefits to farmers and algae producers.

In conclusion, seed and foliar application of $A$. dimorphus aqueous extracts and growth medium had a major positive effect on seed germination and plant growth. However, as with synthetic agrochemicals, there appears to be a cutoff concentration at which higher extract concentrations lead to a decrease in the overall growth and development of tomato plants, compared to lower extract concentrations. Seed inoculation with living $A$. dimorphus culture had the greatest effect on seed germination and seedling growth compared to other treatments. Further studies on the applications of microalgae culture, growth medium, and cell extracts on different plant species are needed. This study demonstrated that there are positive correlations between aqueous foliar sprays and growth of tomato plants.

Application of dry A. dimorphus biomass as a biofertilizer for tomato plants led to an increase in plant growth. Earlier biofertilizer application (22 days prior to transplant) significantly enhanced plant growth, suggesting that earlier application is necessary for the biomass to be broken down in order for nutrients to become available for plant uptake. An application of $50 \mathrm{~g}$ of biofertilizer per plant was sufficient to be both productive and to be potentially feasible from an economic standpoint. Further studies should be conducted to observe how the $A$. dimorphus biomass will react under actual field conditions.

Additional studies on floral crops should be conducted since foliar sprays are commonly utilized within the floriculture industry. Microalgae are an enormous untapped resource with great potential in the agriculture sector, and additional research should be conducted to discover and exploit their potential.

Acknowledgments The authors are grateful to AzCATI for providing the algal biomass used for the study. Jesus Garcia-Gonzalez gratefully acknowledges the financial support provided by the ASU Graduate Professional Student Association (GPSA).

Open Access This article is distributed under the terms of the Creative Commons Attribution 4.0 International License (http:// creativecommons.org/licenses/by/4.0/), which permits unrestricted use, distribution, and reproduction in any medium, provided you give appropriate credit to the original author(s) and the source, provide a link to the Creative Commons license, and indicate if changes were made.

\section{References}

Abdel-Raouf N, Al-Homaidan AA, Ibraheem IBM (2012) Agricultural importance of algae. Afr J Biotechnol 11:11648-11658

AnalystSoft Inc (2009) StatPlus:mac - statistical analysis program for Mac OS. Version 2009. See www.analystsoft.com/en/

Borowitzka MA (2013) High-value products from microalgae - their development and commercialisation. J Appl Phycol 25:743-756

Brennan L, Owende P (2010) Biofuels from microalgae - a review of technologies for production, processing, and extractions of biofuels and co-products. Renew Sust Energ Rev 14:557-577

Burkiewicz K (1987) Active substances in the media after algae cultivation. Acta Physiol Plant 9:211-217

Chagnon M, Kreutzweiser D, Mitchell EAD, Morrissey CA, Noome DA, Van der Sluijs JP (2014) Risks of large-scale use of systemic insecticides to ecosystem functioning and services. Environ Sci Pollut Res. doi:10.1007/s11356-014-3277-x

Faheed FA, Abd-El Fattah Z (2008) Effect of Chlorella vulgaris as biofertilizer on growth parameters and metabolic aspects of lettuce plant. J Agric Social Sci 4:165-169

FAOSTAT (2014) FAOSTAT (Database). (Latest update: 07 Mar 2014) Accessed (1 Dec 2014). http://data.fao.org/ref/262b79ca-279c4517-93de-ee3b7c7cb553.html?version=1.0

Fernández V, Eichert T (2009) Uptake of hydrophilic solutes through plant leaves: current state of knowledge and perspectives of foliar fertilization. Crit Rev Plant Sci 28:36-68

Foley AJ, Ramankutty N, Brauman AK, Cassidy SE, Gerber SJ, Johnston M, Mueller DN, O'Connell C, Ray KD, West CP, Balzer C, Bennett ME, Carpenter RS, Hill J, Monfreda C, Polasky S, Rockstrom J, Sheeban J, Siebert S, Tilman D, Zaks PD (2011) Solutions for a cultivated planet. Nature 478:337-342

Godfray JHC, Beddington RJ, Crute RI, Haddad L, Lawrence D, Muir FJ, Pretty J, Robinson S, Thomas MS, Toulmin C (2010) Food security: the challenge of feeding 9 billion people. Science 327 : $812-818$

Grzesik M, Romanowska-duda Z (2014) Improvements in germination, growth, and metabolic activity of corn seedlings by grain conditioning and root application with cyanobacteria and microalgae. Pol J Environ Stud 23:1147-1153 
Hallmann CA, Foppen RPB, van Turnhout CAM, de Kroon H, Jongejans E (2014) Declines in insectivorous birds are associated with high neonicotinoid concentrations. Nature 511:341-343

Haynes RJ, Goh KM (1977) Review on physiological pathways of foliar absorption. Sci Hortic 7:291-302

Hernández-Herrera RM, Santacruz-Ruvalcaba F, Ruiz-López MA, Norrie J, Hernández-Carmona G (2013) Effect of liquid seaweed extracts on growth of tomato seedlings (Solanum lycopersicum L.). J Appl Phycol 26:619-628

Herrero M, Cifuentes A, Ibanez E (2006) Sub- and supercritical fluid extraction of functional ingredients from different natural sources: plants, food-by-products, algae and microalgae: a review. Food Chem 98:136-148

Irisarri P, Gonnet S, Monza J (2001) Cyanobacteria in Uruguayan rice fields: diversity, nitrogen fixing ability and tolerance to herbicides and combined nitrogen. J Biotechnol 91:95-103

Jha MN, Prasad AN (2006) Efficacy of new inexpensive cyanobacterial biofertilizer including its shelf-life. World J Microbiol Biotechnol 22:73-79

Kannan S, Charnel A (1986) Foliar absorption and transport of inorganic nutrients. Crit Rev Plant Sci 4:341-375

Kawalekar SJ (2013) Role of biofertilizers and biopesticides for sustainable agriculture. J Biol Innov 2:73-78

Köhler H-R, Triebskorn R (2013) Wildlife ecotoxicology of pesticides: can we track effects to the population level and beyond? Science 341:759-765

Kumar G, Sahoo D (2011) Effect of seaweed liquid extract on growth and yield of Triticum aestivum var. Pusa Gold. J Appl Phycol 23:251255

Kumari R, Kaur I, Bhatnagar AK (2011) Effect of aqueous extract of Sargassum johnstonii Setchell \& Gardner on growth, yield and quality of Lycopersicon esculentum Mill. J Appl Phycol $23: 623-633$

Mata TM, Martins AA, Caetano NS (2010) Microalgae for biodiesel production and other applications: a review. Renew Sust Energ Rev 14:217-232

Mendiola JA, Jaime L, Santoyo S, Reglero G, Cifuentes A, Ibañez E, Señoráns FJ (2007) Screening of functional compounds in supercritical fluid extracts from Spirulina platensis. Food Chem 102:13571367

Metting B (1990) Microalgae applications in agriculture. J Ind Microbiol 31:265-270

Odegard RYI, van der Voet E (2014) The future of food - scenarios and the effect on natural resource use in agriculture in 2050. Ecol Econ 97:51-59
Pereira I, Ortega R, Barrientos L, Moya M, Reyes G, Kramm V (2008) Development of a biofertilizer based on filamentous nitrogen-fixing cyanobacteria for rice crops in Chile. J Appl Phycol 21:135-144

Plaza M, Santoyo S, Jaime L, García-Blairsy Reina G, Herrero M, Señoráns FJ, Ibáñez E (2010) Screening for bioactive compounds from algae. J Pharm Biomed Anal 51:450-455

Pragya N, Pandey KK, Sahoo PK (2013) A review on harvesting, oil extraction and biofuels production technologies from microalgae. Renew Sust Energ Rev 24:159-171

Rodríguez-Meizoso I, Jaime L, Santoyo S, Señoráns FJ, Cifuentes A, Ibáñez E (2010) Subcritical water extraction and characterization of bioactive compounds from Haematococcus pluvialis microalga. J Pharm Biomed Anal 51:456-463

Shaaban MM (2001) Nutritional status and growth of maize plants as affected by green microalgae as soil additives. OnLine J Biol Sci 6:475-479

Sharma NK, Tiwari SP, Tripathi K, Rai AK (2010) Sustainability and cyanobacteria (blue-green algae): facts and challenges. J Appl Phycol 23:1059-1081

Shukla AC, Gupta AB (1967) Agriculture: influence of algal growthpromoting substances on growth, yield and protein contents of rice plants. Nature 744

Stanier RY, Kunisawa R, Mandel M, Cohen-Bazire G (1971) Purification and properties of unicellular blue-green algae (order Chroococcales). Bacteriol Rev 35:171-205

Stirk WA, Ördög V, Novák O, Rolčík J, Strnad M, Bálint P, van Staden J (2013) Auxin and cytokinin relationships in 24 microalgal strains. J Phycol 49:459-467

Tarakhovskaya ER, Maslov YI, Shishova MF (2007) Phytohormones in algae. Russ J Plant Physiol 54:163-170

Tilman D, Cassman GK, Matson AP, Naylor R, Polasky S (2002) Agricultural sustainability and intensive production practices. Nature 418:671-677

Van der Sluijs JP, Amaral-Rogers V, Belzunces LP, Bijleveld van Lexmond MFIJ, Bonmatin JM, Chagnon M, Wiemers M (2014) Conclusions of the worldwide integrated assessment on the risks of neonicotinoids and fipronil to biodiversity and ecosystem functioning. Environ Sci Pollut Res. doi:10.1007/s11356-014-3229-5

Verkleij FN (1992) Seaweed extracts in agriculture and horticulture: a review. Biol Agric Hortic 8:309-324

Wijffels RH, Barbosa MJ (2010) An outlook on microalgal biofuels. Science 329:796-799

Zhang W, Yamane H, Takahashi N, Chapman DJ, Phinney BO (1989) Identification of a cytokinin in the green alga Chara globularis. Phytochemistry 28:337-338

Zodape ST (2001) Seaweeds as a biofertilizer. J Sci Ind Res 60:378-382 